\title{
laborhifórico
}

ISSN 2359-6910

https://revistas.ufrj.br/index.php/lh/

FONTES PRIMÁRIAS

Recebido em 20 de dezembro de 2020

Aprovado em 4 de fevereiro de 2021

\section{"Não há necessidade alguma de comunicação telefônica entre os dois estabelecimentos": da Academia Imperial de Belas Artes (AIBA) para o Ministério do Império}

DOI: https://doi.org/10.24206/lh.v7i1.39995

Solange Ribeiro Viegas

Mestre em Preservação e Gestão do Patrimônio Cultural das Ciências e da Saúde (2018) pela Fundação Oswaldo Cruz (FIOCRUZ), Mestre em Ciência da Educação pela Universidade Americana - Assunção (2016), Especialista em Orientação Educacional pela Faculdade de Humanidades Pedro II. Bacharel em Biblioteconomia e Documentação pela Universidade Federal Fluminense (1988). É bibliotecária-documentalista da Universidade Federal do Rio de Janeiro. Atua na área de preservação documental. Coordena o Laboratório de Desenvolvimento de Técnicas de Conservação de Documentos da Biblioteca José de Alencar (BJA) da UFRJ. Pesquisadora na linha da conservação preventiva. Inventora do Módulo de Higienização Multifuncional. Desenvolve atividades de Educação Patrimonial.

E-mail: solangeviegas@letras.ufrj.br ORCID: https://orcid.org/0000-0002-4136-0358 


\section{RESUMO}

Este trabalho tem como objetivo apresentar a transcrição de um manuscrito, pertencente ao Arquivo do Museu D. João VI/-EBA/-UFRJ. Trata-se de um documento escrito em língua portuguesa, datado de 4 de novembro 1886, da Academia Imperial de Belas Artes, destinado ao Ministério do Império, no qual o autor identificado é Antônio Nicolau Tolentino, que solicita o desligamento de uma linha telefônica entre as duas instituições. O documento é contextualizado historicamente, na primeira parte do texto. A indicação das normas utilizadas na transcrição e a transcrição do manuscrito, na segunda parte. Uma análise baseada na transcrição do manuscrito e a identificação de elementos que se referem à estrutura dos signos, como morfologia, módulo e materialidade, são apresentadas na terceira parte do trabalho. Ressaltamos a importância do testemunho como fonte para estudos do contexto tecnológico do Brasil Império. Espera-se que o texto sirva como fonte primária para estudos diversos.

Palavras-chave: Paleografia. Transcrição de manuscritos. Linhas telefônicas. Brasil Império. Academia Imperial de Belas Artes. 


\section{Apresentação}

A Paleografia é um saber fundamental para a o estudo da história da cultura escrita. Surge, no século XVII, como disciplina caudatária e auxiliar da diplomática e, principalmente a partir do século $\mathrm{XX}$, adquire autonomia e papel fundamental para, de maneira multidisciplinar, colocar-se como imprescindível no estudo da história da cultura escrita.

É o paleógrafo Armando Petrucci quem inaugura, em 1962, estudos que renovam o método paleográfico, traçando coordenadas para a saída do isolamento erudito em que estava imersa a paleografia, incorporando às quatro questões fundamentais da paleografia tradicional, que tratam da produção dos testemunhos escritos - o que, quando, onde e como - duas novas perguntas: quem escreve e por que se escreve, as quais teriam resultado em uma mudança substancial da interpretação paleográfica dos produtos escritos (CASTILLO GÓMEZ, 2016, p. 177).

Dentro desse contexto, este trabalho seguiu tais orientações para a transcrição do documento e os questionamentos apresentados pela professora Huda Santiago (Universidade Estadual de Feira de Santana), durante as aulas da disciplina Filologia Portuguesa e Crítica Textual do Programa de PósGraduação em Letras Neolatinas da Faculdade de Letras da Universidade Federal do Rio de Janeiro, no primeiro semestre de 2020, sendo eles: como reconstruir o perfil de um escrevente do passado? Como reconstruir sua história a partir de indícios do seu próprio texto? Como reconhecer um texto escrito por escreventes pouco treinados na técnica de escrita alfabética? Como identificar o grau de domínio da técnica de escrita dos escreventes, em um dado espaço tempo?

O manuscrito selecionado é um documento avulso, e pertence ao Arquivo do Museu D. João VI. Trata-se de uma correspondência, com data de 4 de novembro de 1886, da Academia Imperial de Belas Artes (AIBA) para o Ministério do Império, tendo como representante o Barão de Mamoré, Ambrósio Leitão da Cunha, que foi senador do império de 1870 a 1889.

O autor identificado é Antonio Nicolau Tolentino, que ocupou diversos cargos públicos. Trabalhou como funcionário do Tesouro Nacional, presidiu a Caixa Econômica e foi diretor da Academia de Belas Artes entre os anos de 1874 a 1888.

A correspondência aborda o desligamento da linha telefônica entre a AIBA e a Secretaria do Império. $\mathrm{O}$ argumento para o desligamento é a proximidade entre as instituições, que era de três minutos. Desta forma, buscamos, em fontes bibliográficas, a fim de contextualizar o documento, dados históricos sobre as instituições, implantação de linhas telefônicas no Brasil Império e dados biográficos para construir o perfil de quem escreveu e do destinatário. Portanto, além dos aspectos paleográficos propriamente ditos do manuscrito, é preciso situá-lo também no tempo e no espaço. 
A AIBA foi uma escola superior de arte fundada no Rio de Janeiro, Brasil, por Dom João VI. Hoje é a Escola de Belas Artes da Universidade Federal do Rio de Janeiro. Teve um papel importante na difusão da cultura nacional e contava com apoio financeiro do Imperador Dom Pedro II.

Para além do texto contido no documento, é importante destacar que no dia 4 de julho de 1876, Dom Pedro II esteve presente na Exposição Universal da Filadélfia, na qual o telefone, invenção de Graham Bell, estava sendo exposto. D. Pedro II foi o primeiro brasileiro ao falar ao telefone e exclamou "Meu deus, isto fala!". A implementação das linhas telefônicas no Brasil ocorreu um ano depois, em 1877, ainda no Brasil império, já que o Imperador tinha interesse nas novas tecnologias e nas ciências visando questões de progresso, desenvolvimento e civilização do país.

No início, as linhas telefônicas no Brasil foram instaladas somente para comunicação entre repartições do governo, órgãos militares e corpo de bombeiro. A partir de 1882, o governo imperial estabeleceu decretos que ampliaram a capacidade de telefonia para todo o território nacional, sendo a Companhia União Telefônica do Brasil comtemplada para concessão. No documento, Tolentino chama a atenção para o valor de 40 mil reis, pago a essa companhia, sendo 10 mil reis mensais referentes aos meses de junho, agosto, setembro e outubro. E solicita o desligamento da linha, pois não via necessidade alguma de comunicação telefônica entre as instituições, já que eram muito próximas.

\section{Normas técnicas para transcrição e edição de documentos manuscritos}

Para a transcrição do documento, tomamos por base as Normas Técnicas para Transcrição e Edição de Documentos Manuscritos, de 1993, disponíveis em Berwanger e Leal (2015, p. 97-106). As normas utilizadas foram:

(1) Serão separadas as palavras grafadas unidas indevidamente e serão unidas as sílabas ou letras grafadas separadamente, mas de forma indevida;

(2) As abreviaturas não correntes deverão ser desenvolvidas com os acréscimos em grifo;

(3) Quando a leitura paleográfica de uma palavra for duvidosa, colocar-se-á uma interrogação entre colchetes depois da mesma: [?];

(4) A acentuação será conforme o original;

(5) A pontuação original será mantida; 
(6) As maiúsculas e minúsculas serão mantidas;

(7) A ortografia será mantida na íntegra, não se efetuando nenhuma correção gramatical;

(8) As palavras que se apresentam parcial ou totalmente ilegíveis, mas cujo sentido textual permita a sua reconstituição, serão impressas entre colchetes;

(9) As palavras ilegíveis para o transcritor serão indicadas com a palavra ilegível entre colchetes e grifada: [ilegível];

(10) Os elementos textuais interlineares ou marginais autógrafos que completam o escrito serão inseridos no texto entre os sinais <...>;

(11) Quando não forem autógrafos, serão indicados em nota de rodapé;

(12) As notas marginais, não inseríveis no texto, serão mantidas em seu lugar ou em sequência ao texto principal com a indicação: à margem direita ou à margem esquerda;

(13) As notas de mão alheia serão transcritas em rodapé;

(14) As assinaturas em raso ou rubricas serão transcritas em grifo;

(15) Os caracteres impressos que aparecem em documentos mistos recentes serão transcritos em tipos diferentes. Incluem-se aqui os formulários, timbres, fichas-padrão, carimbos, siglas etc;

(16) A transcrição dos documentos poderá ser linha por linha ou de forma corrida;

(17) Será respeitada a divisão paragráfica do original. 


\section{Edição do documento}

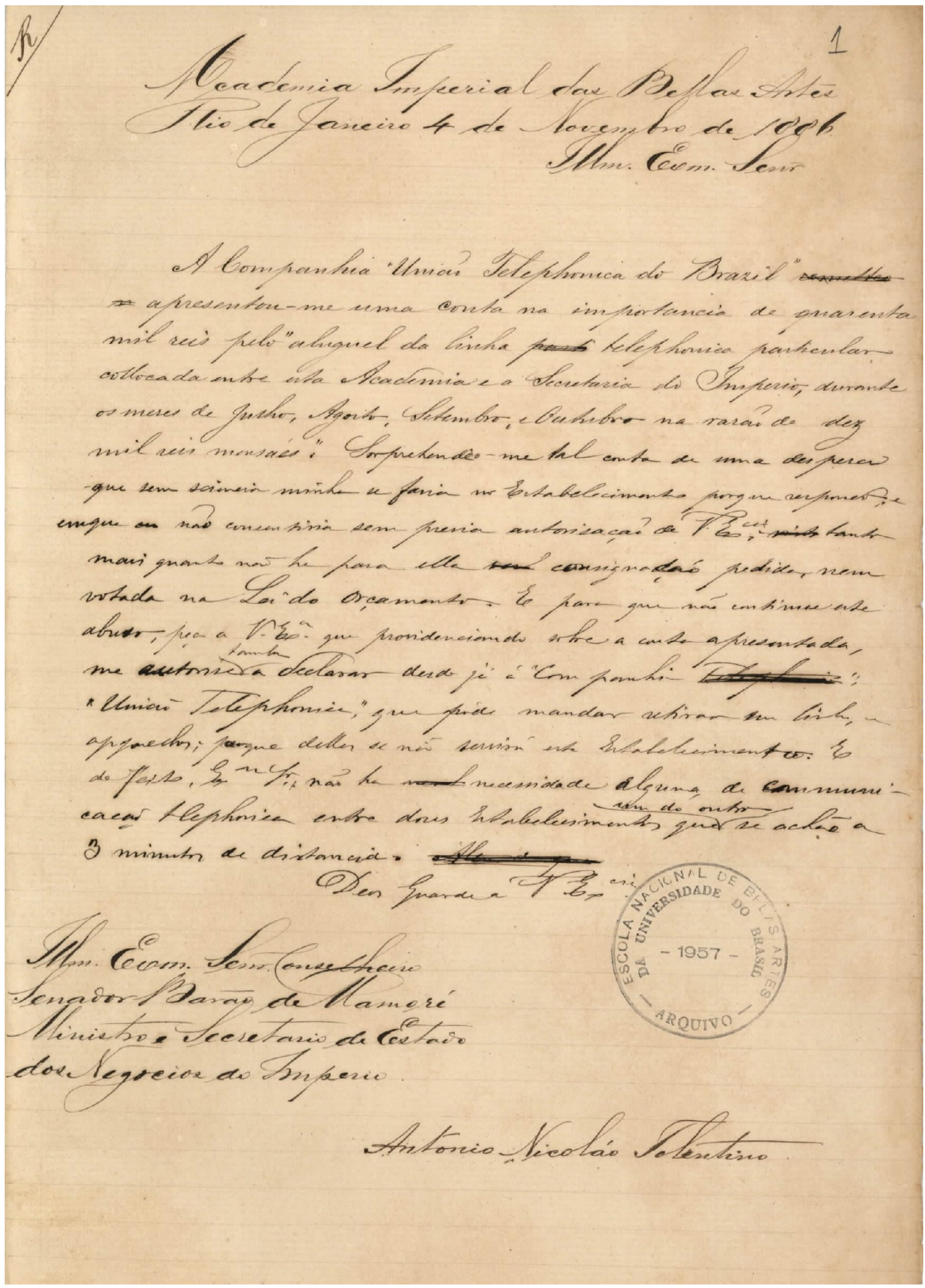

Fonte: Arquivo do Museu D. João VI / EBA / UFRJ. Avulsos. Documento 001. 
Academia ${ }^{1}$ Imperial das Bellas Artes ${ }^{2}$

Rio de Janeiro 4 de novembro de 1886

Illustríssimo Excelentíssimo Senhor

A Companhia "Uniaõ Telephonica do Brazil “ [ilegível]

[ilegível] apresentou-me uma conta na importancia de quarenta mil reis pelo "aluguel da linha [parti] telephonica particular collocada entre esta Academia e a Secretaria do Imperio, durante os meses de Junho, Agosto, Setembro, e Outubro na rasaõ de dez mil reis mensaes." Sorprehendêo-me tal conta de uma despesa que sem [ilegível] minha se faria no Estabelecimento porque [ilegível] e em que eu naõ consentiria sem previa autorisaçaõ de Vossa Excelência, [ilegível] tanto mais quanto não he para ella [ilegível] consignaçaõ pedida, nem votada na Lei do orçamento. E para que não continue este abuso, peço a Vossa Excelência que providenciando sobre a causa apresentada, me autorise $<$ tambem $>$ a declarar desde já a "Companhia [Telephonica]." "União Telephonica," que pode mandar retirar sua linha, e [ilegível]; porque delles se não serviam este Estabelecimento. E desfeito, Excelentíssimo Senhor naõ ha [nenh] necessidade alguma de communicação telephonica entre dois Estabelecimentos que $<$ um do outro $>$ se achaõ a

3 minutos de distancia. [ilegível]

\section{Deos Guarde a Vossa Excelência ${ }^{3}$}

Illustríssimo Excelentíssimo Senhor Conselheiro

Senador Barão de Mamoré

dos Negreios do Imperio.

Antonio Nicoláo Tolentino

\footnotetext{
${ }^{1}$ À esquerda do título encontra-se escrito por outro punho a consoante "R".

2 À direita do título encontra-se escrito por outro punho o número " 1 ".

${ }^{3}$ Carimbo do Arquivo da Escola Nacional de Belas Artes da Universidade do Brasil, 1957.
} 


\section{Comentários paleográficos}

Esta seção tem como objetivo informar como foi elaborada a transcrição e destacar as características peculiares do manuscrito. A transcrição foi feita linha por linha, respeitando a divisão paragráfica original e seguindo o modelo de translineação, com números sequenciais de cinco em cinco, colocados à margem esquerda. Nos casos em que a linha excedeu a pauta, foi utilizada pauta imediata, sem numeração.

De acordo com Núñez Contreras (1994, p. 38) os elementos constitutivos da escritura são: (i) os que se referem propriamente à estrutura dos signos: morfologia, ângulo, ductos, módulos, ligadura e nexos; outros elementos são: estilo, matéria subjetiva e caracteres internos. Para esta pesquisa foram contemplados alguns desses elementos, como determinados aspectos morfológicos.

$\mathrm{Na}$ transcrição, a pontuação e a acentuação foram mantidas conforme o original. Palavras que foram suprimidas dentro do texto, "riscadas /ilégiveis", foram indicadas, entre colchetes, pela palavra ilegível. Foram separadas as palavras grafadas unidas indevidamente, mas mantendo-se sua ortografia original, sem correção gramatical, como "emque", na linha 12 do manuscrito.

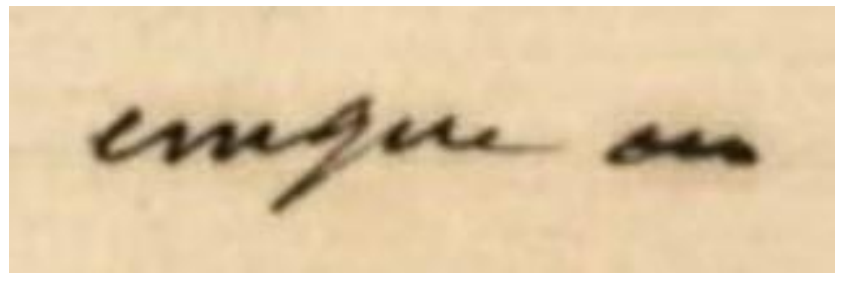

Foram desenvolvidas as abreviaturas presentes no texto, grifando as letras omitidas, como por exemplo.

Linha 3: Illustríssimo Excelentíssimo Senhor

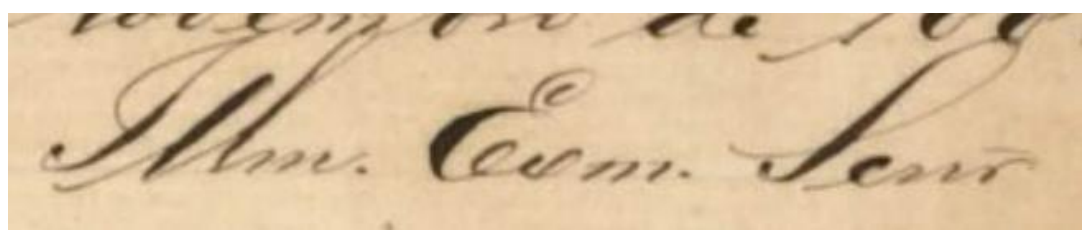

Linha 15: Vossa Excelência

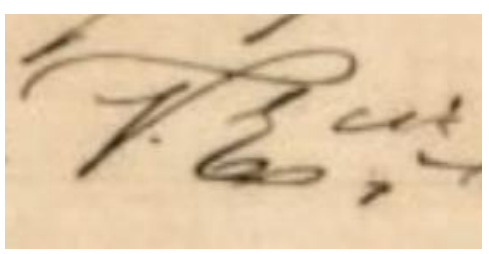


Linha 23: Illustríssimo Excelentíssimo Senhor Conselheiro

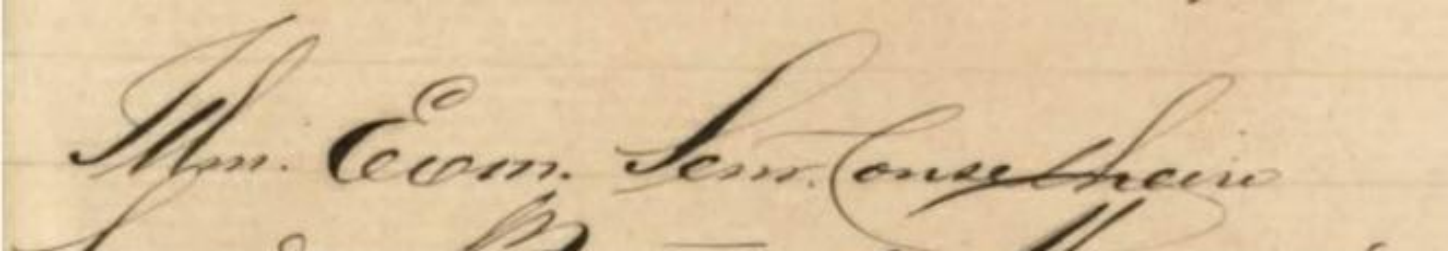

A assinatura foi transcrita por extenso e foi grifada, seguindo as normas de transcrição.

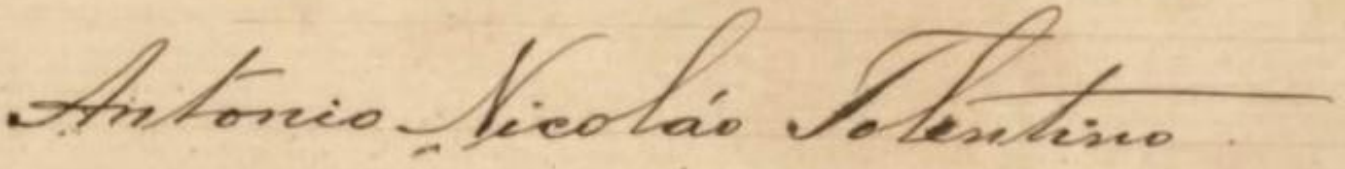

Nos chama atenção o fato de no documento o nome Nicoláo estar grafado com a vogal "o" na posição final, mas, nas pesquisas bibliográficas, ser identificado como Nicolau, tendo a vogal "u" em posição final.

Os elementos textuais interlineares que complementam o documento foram inseridos no texto entre barras oblíquas opostas < >, conforme podemos observar na linha $16<$ tambem> e na linha 20 $<$ um do outro>.

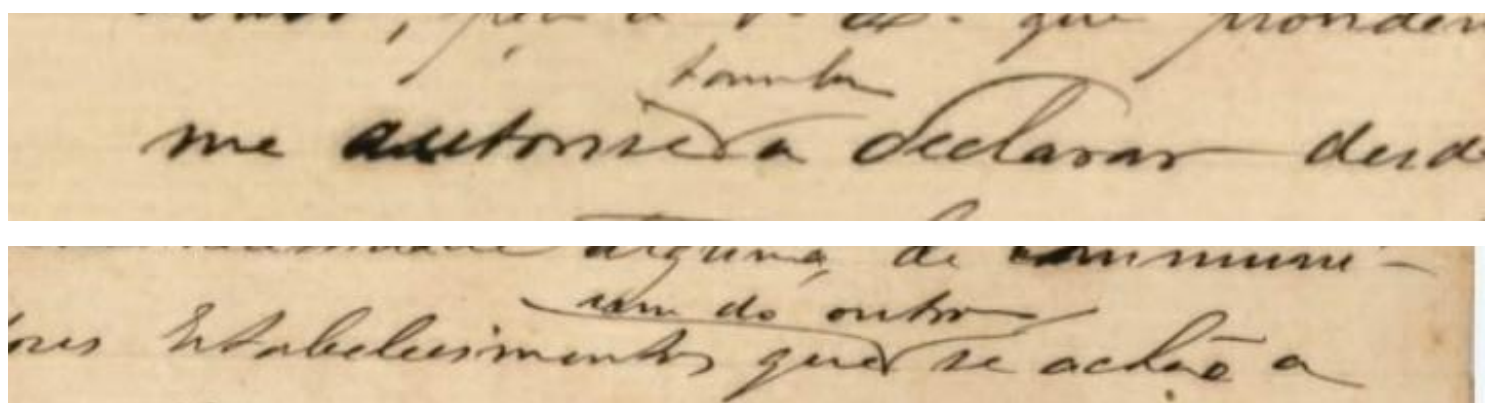

No que diz respeito ao módulo, uma categoria paleográfica que está relacionada com a dimensão da forma das letras, no documento foi constatada a uniformidade no tamanho das letras. O peso está relacionado ao traçado constitutivo de cada letra, podendo ser fino ou grosso. Neste aspecto, o peso da mão é quase constante, apresentando traçado mais grosso nas letras maiúsculas no título e no destinatário no final do documento.

Ainda em relação aos aspectos morfológicos, distinguem-se as letras maiúsculas das minúsculas. Por fim, cabe dizer que o tipo de letra utilizada no manuscrito pode ser classificado como Humanística Cursiva. 
Em relação à materialidade, o manuscrito apresenta um bom estado de conservação, sem rasgos e fissuras. Provavelmente foi escrito em papel madeira. Por meio da análise realizada no carimbo, em forma de círculo fixado no final do documento no lado direito, vê-se que o ano de registro de entrada no Arquivo Nacional da Escola de Belas Artes foi em 1957.

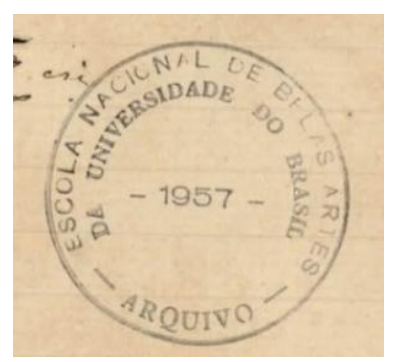

\section{Considerações finais}

O texto aqui transcrito e apresentado fez parte da avaliação da disciplina Filologia Portuguesa e Crítica Textual oferecida pelo professor Leonardo Marcotulio (UFRJ) e pela professora Huda Santiago (UEFS), no Programa de Pós-Graduação em Letras Neolatinas da Faculdade de Letras da UFRJ.

Os comentários sobre a transcrição poderão servir de base para outras transcrições. Para melhor compreensão do texto foi preciso situá-lo também no tempo e no espaço. O conteúdo do documento transcrito é muito relevante, pois por meio dele foi possível retratar um período da história da comunicação no Brasil império. Espera-se que o texto transcrito sirva como fonte primária para estudos diversos. 


\section{Referências bibliográficas}

ACKEL, A. Estudo Paleográfico de Manuscrito do Século XVII. Revista todas as letras, São Paulo, v. 21, p. 06-17, 2019.

BARBOSA, A. G. O controle de marcas de inabilidade na escrita alfabética e a identificação das mãos inábeis em corpora histórico-diacrônicos. Revista da ABRALIN, v.16, n.2, p. 19-43, Jan./Fev./Mar./Abril de 2017

BERWANGER, A. R.; LEAL, J. E. F. Normas Técnicas para Transcrição e Edição de Documentos Manuscritos. In: Noções de Paleografia e de Diplomática. 5a ed. Santa Maria: Editora UFSM, 2015. p. 97-106.

CASTILLO GÓMEZ, A.; SÁEZ, C. Paleografia versus Alfabetização. Reflexões sobre História Social da Cultura Escrita. LaborHistórico, v. 2, n. 1, p. 164-187, 2016.

MARQUILHAS, R. Norma Gráfica Setecentista - do Autógrafo ao Impresso. Lisboa: INIC, série Linguística, n. 14, 1991.

NACIONALIDADE BRASILEIRA. Disponível em: https://pt.wikipedia.org/wiki/Nacionalidade_brasileira. Acesso em: 2 dez 2020.

NÚÑEZ CONTRERAS, L. Manual de Paleografía. Fundamentos e história de la escritura latina hasta el siglo VIII. Madrid: Cátedra, 1994.

PEREIRA, Sonia Gomes. Artes ensino e academia: Estudos e ensaios sobre a Acadêmia de Belas Artes do Rio de Janeiro. Rio de janeiro: Faperj, 2016.

PETRUCCI, A. La ciencia de la escritura: primera lección de paleografía. Buenos Aires: Fondo de Cultura Económica de Argentina, 2003.

SANTIAGO, H. da S.; CARNEIRO, Z. de O. N. Tratamento metodológico das mãos inábeis em corpora diacrônicos. In: CASTILHO, A. T. de. (Coord.). História do Português Brasileiro. v. 2. Corpus diacrônico do português brasileiro. São Paulo: Contexto, 2019. p. 92-119.

SANTIAGO. H. da S. A escrita por mãos inábeis: uma proposta de caracterização. Tese (Doutorado em Língua e Cultura) - Programa de Pós-graduação em Língua e Cultura, Universidade Federal da Bahia, Salvador, 2019. Disponível em: https://repositorio.ufba.br/ri/handle/ri/29323. Acesso em: 2 dez 2020. 